\title{
The time course of orthographic and phonological code activation in the early phases of visual word recognition
}

\author{
LUDOVIC FERRAND and JONATHAN GRAINGER \\ Centre National de la Recherche Scientifique \\ and René, Descartes University, Paris, France
}

\begin{abstract}
In a recent article, Ferrand and Grainger (1992) reported that briefly presented, forward-masked, nonword primes that share letters with a target word facilitate lexical decision performance at prime exposures of $33 \mathrm{msec}$, but no longer affect performance at 67 -msec exposures. In the same experiment, nonword primes that were homophonic with targets did not affect performance relative to orthographic controls at 33-msec prime exposures, but produced facilitatory priming effects at prime exposures of $67 \mathrm{msec}$. In the present study, we extend these results, varying prime exposures from $17 \mathrm{msec}$ to $100 \mathrm{msec}$. Orthographic facilitation was found with prime exposures from $17 \mathrm{msec}$ to $50 \mathrm{msec}$, whereas phonological facilitation only started to emerge at exposures of $50 \mathrm{msec}$. The results demonstrate a distinct time course for the buildup of orthographic and phonological information during the processing of pronounceable strings of letters.
\end{abstract}

Recent data on visual word recognition suggest that phonological information facilitates performance in visual word recognition tasks such as perceptual identification (Lukatela \& Turvey, 1990a; Perfetti \& Bell, 1991; Perfetti, Bell, \& Delaney, 1988) and lexical decision (Ferrand \& Grainger, 1992, 1993; Lukatela, Carello \& Turvey, 1990; Lukatela \& Turvey, 1990b). All these studies used visual masking and/or priming procedures with very brief prime presentation durations. For instance, Perfetti et al. (1988) reported that the percentage of correct identifications for phonologically primed targets (e.g., MADE primed by a nonword that sounds like the target word, MAYD) was significantly higher than that obtained for orthographically primed targets (e.g., MADE primed by MARD). Lukatela and Turvey (1990a), using a similar backward masking paradigm, reported the same pattern of results for Serbo-Croatian. More recently, Perfetti and Bell (1991) varied prime presentation duration from $25 \mathrm{msec}$ to $65 \mathrm{msec}$ in a forward-masked, primed perceptual identification task. They observed orthographic effects already present at prime exposures of $35 \mathrm{msec}$, whereas phonological effects only emerged at $45-\mathrm{msec}$ exposures. The above experiments all converge to suggest that these facilitatory effects are due to the automatic, prelexical activation of phonological information in visual word recognition.

Using a masked priming procedure with the lexical decision task, Ferrand and Grainger (1992) observed only

\footnotetext{
The research reported in this article was run while the first author was doing his military service. He would like to thank the members of the Laboratory of Experimental Psychology in Paris for their support during this period. Correspondence should be addressed to L. Ferrand, Laboratoire de Psychologie Expérimentale, 28 rue Serpente, 75006 Paris, France (e-mail: upec010@frors31.bitnet).
}

orthographic facilitation and no phonological facilitation with a 33-msec prime duration. However, with a 67-msec prime exposure, Ferrand and Grainger replicated the existence of phonological priming previously observed in perceptual identification (Perfetti \& Bell, 1991; Perfetti et al., 1988) and lexical decision (Lukatela \& Turvey, 1990b; Lukatela et al., 1990). This phonological facilitation was obtained in conditions where no orthographic facilitation was observed and was independent of targetword frequency and of the presence or absence of pseudohomophone targets in the experimental lists. The results suggest that these phonological effects are, indeed, automatic and not strategically driven.

Ferrand and Grainger (1992) interpreted this pattern of orthographic and phonological priming effects within the framework of an extended version of the interactive activation model initially developed by McClelland and Rumelhart (1981). The architecture of the extended model is characterized by a triangular organization. It includes a layer of sublexical orthographic units linked to a layer of sublexical phonological units, both of which are connected to a level of lexical representations (word level). This triangular organization, therefore, involves direct connections from orthographic units to both word units and phonological units, phonological units also being directly connected to the word level. On presentation of a written word, the visual input activates a set of orthographic units (letters or letter clusters), which in turn send activation on to those word units and phonological units that are directly linked to the activated orthographic units. In this way, the buildup of activation at the lexical and phonological levels lags behind the buildup of activation at the orthographic level. This means that at very short prime exposures (e.g., $33 \mathrm{msec}$ ), only orthographic units will be sufficiently activated to facilitate subsequent tar- 
get recognition. With longer prime exposures (e.g., $67 \mathrm{msec}$ ), however, both phonological units and word units will be more activated and, hence, capable of influencing subsequent target recognition. Activated word units will inhibit target-word recognition via within-level inhibition, whereas activated phonological units will provide facilitatory input to the target representation and, hence, facilitate recognition. Thus, at prime exposures of around $60 \mathrm{msec}$, facilitatory effects of phonological prime-target overlap are present, but the facilitatory effects of orthographic overlap are canceled by within-level lexical inhibition.

According to this conception of the visual word recognition process, orthographic information contacts lexical representations before phonological information does, even if it is clear that phonology influences the early phases of visual word recognition. Assuming this, we predict different growth functions for orthography and phonology, with orthographic facilitation growing earlier and decaying earlier than phonological facilitation. To test this prediction, four prime exposure durations are tested in the following experiment to complement the two exposure durations studied by Ferrand and Grainger (1992). The resulting six prime exposures $(17,33,50,67,83$, and $100 \mathrm{msec}$ ) were submitted to a combined analysis.

\section{METHOD}

\section{Subjects}

One hundred and twenty psychology students at René Descartes University, Paris, served as subjects for course credit, 30 in each of the four prime duration conditions $(17,50,83$, and $100 \mathrm{msec})$. All were native speakers of French, with normal or corrected-to-normal vision.

\section{Stimuli and Design}

The stimuli from Ferrand and Grainger's (1992) study were used here. These consisted of 60 French word targets, all four letters long, half with high printed frequencies and half with low printed frequencies (461 and 17 occurrences per million, respectively; Trésor de la langue Française, 1971). Each target word was preceded by three types of nonword prime: (1) nonword primes that were both orthographically related (differing by only one letter in any position) and homophonic with the target (e.g., lont-LONG, pronounced identically in French); (2) nonword primes that were orthographically related (in the same way as in Category 1, but not homophonic with the target (e.g., lonc-LONG); and (3) nonword primes that were unrelated (both orthographically and phonologically) to the target (e.g., tabe-LONG). Priming condition was crossed with target frequency. Four prime durations were used: 17, 50, 83 , and $100 \mathrm{msec}$. Priming condition was crossed with prime duration as a between-subject factor. Prime-target pairs were rotated across the priming conditions across three groups of subjects (for each prime duration) such that no subject saw any single prime or target more than once, but each subject received all three priming conditions. Every subject saw 60 nonword prime/word target pairs, 10 from each condition, and 60 nonword prime/nonword target pairs. The subjects were presented with 20 practice trials before the experiment proper. These consisted of 10 nonword-word and 10 nonword-nonword pairs, none of which appeared in the experimental trials, all four letters long and selected from the same frequency range as the experimental stimuli.

\section{Procedure}

Stimuli were presented in isolation on the center of the screen of a personal computer with a $60-\mathrm{Hz}$ refresh rate. The masked prime procedure with the lexical decision task used in the experiments of Ferrand and Grainger (1992) was adopted here. Each trial consisted of the following sequence: First, a forward mask consisting of a row of four hash marks $(\# \# \# \#)$ was presented for $500 \mathrm{msec}$. This was followed immediately by the presentation of the prime stimulus (for $17,50,83$, or $100 \mathrm{msec}$ ), which was followed immediately by the presentation of the target stimulus. Both were presented in the same screen location as the mask. The target remained on the screen until the subjects responded. Primes were always presented in lowercase and targets in uppercase to minimize physical overlap with orthographically related pairs. The subjects were instructed to answer as rapidly and as accurately as possible whether or not the letter string in uppercase that remained on the screen was a French word. The existence of a prime stimulus was not mentioned. The subjects responded "yes" by pressing one of two response buttons with the forefinger of the preferred hand and "no" by pressing the other response button with the forefinger of the nonpreferred hand. The next sequence followed after a 1-sec delay. Stimulus presentation was randomized, with a different order for each subject. Reaction times, measured from target onset until subject's response, were accurate to the nearest millisecond.

\section{RESULTS}

Mean lexical decision latencies and percent errors are given in Table 1 for each prime duration. The latencies were trimmed, applying a 1,000 -msec cutoff $(2.2 \%$, $1.8 \%, 2.1 \%$, and $2.9 \%$, respectively, of the data rejected for each prime duration). These data were combined with the results of Ferrand and Grainger (1992) to give a total of six prime exposure durations. An analysis of variance (ANOVA) of the reaction time data was performed, with priming condition (homophonic and orthographically similar prime, orthographically similar prime, unrelated prime), prime duration, and target frequency as main factors; $F$ values are reported by subject $(F 1)$ and by item $(F 2)$.

There were significant main effects of priming condition $[F 1(2,348)=32.6, p<.001 ; F 2(2,116)=20.61$, $p<.001]$, prime duration $[F 1(5,174)=3.14, p<.01$; $F 2(5,290)=41.47, p<.001]$, and target frequency $[F 1(1,174)=259.22, p<.0001 ; F 2(1,58)=18.44$, $p<.0001]$. Priming condition interacted significantly with prime duration $[F 1(10,348)=1.99, p<.05$; $F 2(10,580)=1.53$ ]. None of the other interactions between these three factors was significant (all $\left.F_{\mathrm{s}}<1\right)$. An ANOVA performed on the error data for the word targets showed no main effects (all $F \mathrm{~s}<1$ ) except for the word-frequency effect $[F(1,174)=35.35, p<.001]$.

Planned comparisons between orthographic primes and unrelated controls (i.e., effects of orthographic priming; see Table 1) showed a significant (or marginally significant) effect for prime exposures up to and including $50 \mathrm{msec}$ [at $17 \mathrm{msec}, F 1(1,27)=3.96, .05<p<.10$, and $F 2(1,58)=4.04, p<.05$; at $33 \mathrm{msec}, F 1(1,27)=$ $4.81, p<.05$, and $F 2(1,58)=9.09, p<.005$; at $50 \mathrm{msec}, F 1(1,27)=6.87, p<.05$, and $F 2(1,58)=$ $6.72, p<.05$; at 67, 83, and $100 \mathrm{msec}$, all $F \mathrm{~s}<1]$. On the other hand, planned comparisons between pseudohomophone primes and orthographic controls (i.e., effects of phonological priming; see Table 1) showed a significant effect at prime exposures from $67 \mathrm{msec}$ to $83 \mathrm{msec}$ [at $50 \mathrm{msec}, F 1(1,27)=3.35, .05<p<.10$, and $F 2(1,58)=2.29$; at $67 \mathrm{msec}, F 1(1,27)=15.76, p<$ 
Table 1

Mean Lexical Decision Latencies (RT in Milliseconds) and Percentage of Errors (PE) to Targets Preceded by Phonologically and/or Orthographically Related or Unrelated Nonword Primes Throughout the Six Prime Durations

\begin{tabular}{|c|c|c|c|}
\hline \multirow{2}{*}{$\begin{array}{l}\text { Prime } \\
\text { Duration }\end{array}$} & $\begin{array}{c}\text { Orthographically } \\
\text { Similar } \\
\text { Pseudohomophone } \\
\text { Prime } \\
\end{array}$ & $\begin{array}{c}\text { Orthographically } \\
\text { Similar } \\
\text { Prime } \\
\end{array}$ & $\begin{array}{c}\text { Unrelated } \\
\text { Prime }\end{array}$ \\
\hline & $P E$ & RT & RT \\
\hline
\end{tabular}

High-Frequency Targets

\begin{tabular}{|c|c|c|c|c|c|c|}
\hline \multirow[b]{2}{*}{17} & \multicolumn{2}{|c|}{ e.g., lont-LONG } & \multicolumn{2}{|c|}{ e.g., lonc-LONG } & \multicolumn{2}{|c|}{ e.g., tabe-LONG } \\
\hline & 560 & 2.3 & 555 & 3.3 & 570 & 5.0 \\
\hline $33^{*}$ & 558 & 4.0 & 563 & 7.3 & 593 & 7.3 \\
\hline 50 & 545 & 4.3 & 553 & 4.6 & 570 & 3.0 \\
\hline $67^{*}$ & 582 & 5.3 & 601 & 3.0 & 605 & 3.3 \\
\hline 83 & 589 & 7.8 & 595 & 8.1 & 593 & 8.5 \\
\hline 100 & 623 & 7.7 & 616 & 6.0 & 619 & 4.3 \\
\hline
\end{tabular}

Low-Frequency Targets

\begin{tabular}{|c|c|c|c|c|c|c|}
\hline \multirow[b]{2}{*}{17} & \multicolumn{2}{|c|}{ e.g., klan-CLAN } & \multicolumn{2}{|c|}{ e.g., slan-CLAN } & \multicolumn{2}{|c|}{ e.g., jinc-CLAN } \\
\hline & 608 & 12.3 & 620 & 10.3 & 634 & 12 \\
\hline $33^{*}$ & 599 & 13 & 604 & 14 & 620 & 15.3 \\
\hline 50 & 583 & 12.6 & 603 & 11.3 & 632 & 16 \\
\hline $67^{*}$ & 607 & 11.6 & 641 & 10.6 & 644 & 12.6 \\
\hline 83 & 604 & 15.2 & 631 & 14.8 & 631 & 20.4 \\
\hline 100 & 641 & 12.3 & 667 & 14 & 665 & 13 \\
\hline
\end{tabular}

*Data taken from Ferrand and Grainger (1992).

.001 , and $F 2(1,58)=15.12, p<.001$; at $83 \mathrm{msec}$, $F 1(1,27)=6.68, p<.05$, and $F 2(1,58)=6.45, p<$ .05 ; at 17 and $100 \mathrm{msec}$, all $F \mathrm{~s}<1$; at $33 \mathrm{msec}, F 1(1,27)$ $=1.74$ and $F 2(1,58)<1]$. The priming condition $\times$ target frequency interaction was not significant at each prime duration $[17 \mathrm{msec}$, all $F \mathrm{~s}<1 ; 33 \mathrm{msec}, F 1(2,54)=1.74$ and $F 2<1 ; 50 \mathrm{msec}, F 1(2,54)=1.73$ and $F 2(2,116)$ $=1.31 ; 67 \mathrm{msec}, F 1(2,54)=1.04$ and $F 2<1 ; 83 \mathrm{msec}$, $F 1(2,54)=3.09, .05<p<.10$, and $F 2(2,116)=$ $2.27 ; 100 \mathrm{msec}, F 1(2,54)=2.17$ and $F 2<1]$.

\section{Orthography and Phonology}

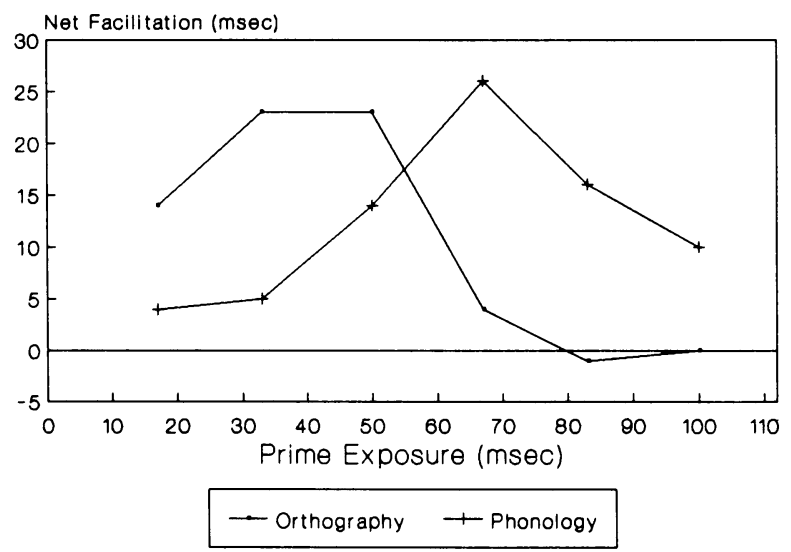

Figure 1. Net effects of phonological priming (pseudohomophone primes compared with orthographic controls) and net effects of orthographic priming (orthographically related primes compared with unrelated controls) as a function of prime exposure duration.
Figure 1 shows the growth functions of orthographic priming and phonological priming as a function of prime exposure. As can be seen, there is a steady increase in the size of orthographic priming effects from 17 to $50 \mathrm{msec}$, which then decrease to zero with longer prime exposures. Phonological priming effects, on the other hand, start to emerge at $50 \mathrm{msec}$, reach a peak at $67 \mathrm{msec}$, and then decrease.

\section{DISCUSSION}

These results show clear facilitatory effects of orthographic and phonological priming that vary as a function of prime exposure duration and are independent of target-word frequency. Concerning phonological facilitation effects, we replicate Perfetti and Bell's (1991) results with reaction time as the dependent measure in a lexical decision task. Moreover, the lexical decision task has allowed us to separate out the orthographic and phonological contributions to these phonological priming effects, something Perfetti and Bell failed to achieve with the perceptual identification paradigm. In that sense, the lexical decision task combined with very short prime exposures seems to be very sensitive to early (prelexical) processes, allowing us to isolate prime durations at which only orthographic effects (i.e., 17 and $33 \mathrm{msec}$ ), and not phonological effects, are observed.

More generally, these results support the hypothesis that both orthographic and phonological information play a fundamental role in the process of visual word recognition and that these different information sources are generated very early. As Perfetti and Bell (1991) and Ferrand and Grainger (1992) have shown, phonological priming effects are independent of word frequency, thus supporting the general hypothesis that prelexical phonology contributes to visual word recognition. The results of this study provide clear evidence that the early phases of visual word recognition are directly influenced by both orthographic and phonological information (see Ferrand \& Grainger, 1993, for a similar conclusion). The present experiment clearly illustrates the different time course of the development of these two codes (see Figure 1). 
These results can be interpreted within the framework of an extended interactive activation model (McClelland \& Rumelhart, 1981) discussed in the introduction (see also Ferrand \& Grainger, 1992). Within this framework, connections between word units are uniquely inhibitory (within-level inhibition), whereas connections between different types of units (orthographic, phonological, word) are primarily facilitatory (between-level facilitation). This framework incorporates the basic principle that the buildup of phonological information lags behind the buildup of orthographic information, while adding the important feature that when phonological information starts to provide feed-forward excitatory input to the lexicon, within-level inhibition is developing at the word level.

After $17 \mathrm{msec}$ of processing on the prime stimulus, orthographic units are starting to be activated. This leads to slight (marginally significant) facilitation in the recognition of target words that share orthographic information with primes. On the other hand, phonological units are not sufficiently activated after $17 \mathrm{msec}$ of processing to affect the subsequent recognition of the target. With extended processing of the prime ( 33 to $50 \mathrm{msec}$ ), the facilitatory effects of orthographic priming develop and become statistically robust, while the facilitatory effects of phonological priming only start to emerge. As processing on the prime continues, word units receive more and more excitatory input from both orthographic and phonological units. The rise in activation of all word units other than the target word itself results in increased lexical inhibition during target processing, counteracting the facilitatory effects of orthographic overlap (from $67 \mathrm{msec}$ to $100 \mathrm{msec}$ ). While lexical inhibition is gradually canceling orthographic facilitation effects, phonological units continue to provide excitatory input to word units, thus giving rise to phonological facilitation effects. However, with extended processing of the prime ( $83 \mathrm{msec}$ and $100 \mathrm{msec})$, lexical inhibition in creases sufficiently to also cancel these facilitatory effects of phonological prime-target overlap. Thus, by $100 \mathrm{msec}$, both orthographic and phonological effects are absent, having been canceled by within-level lexical inhibition.

The present results describe the time course of orthographic and phonological code activation during the early processing of pronounceable strings of letters. They suggest that both orthographic and phonological units mediate access to lexical representations. However, further work is needed to clarify the type of orthographic and phonological units involved in this processing. This is critical for a full implementation of the type of interactive activation model outlined in Ferrand and Grainger (1992).

\section{REFERENCES}

Trésor de la langue Française (1971). Nancy, France: Centre National de la Recherche Scientifique.

Ferrand, L., \& Grainger, J. (1992). Phonology and orthography in visual word recognition: Evidence from masked nonword priming. Quarterly Journal of Experimental Psychology, 45A, 353-372.

FERRAND, L., \& GRAINGER, J. (1993). Effects of orthography are independent of phonology in masked form priming. Manuscript submitted for publication.

lukatela, G., Carello, C., \& Turvey, M. T. (1990). Phonemic, associative, and grammatical context effects with identified and unidentified primes. Language \& Speech, 33, 1-18.

Lukatela, G., \& TURvey, M. T. (1990a). Automatic and pre-lexical computation of phonology in visual word identification. European Journal of Cognitive Psychology, 2, 325-343.

Lukatela, G., \& TURvey, M. T. (1990b). Phonemic similarity effects and prelexical phonology. Memory \& Cognition, 18, 128-152.

McClelland, J. L., \& Rumelhart, D. E. (1981). An interactive activation model of context effects in letter perception: Part 1. An account of basic findings. Psychological Review, 88, 375-407.

Perfetti, C. A., \& Bell, L. (1991). Phonemic activation during the first $\mathbf{4 0} \mathrm{ms}$ of word identification: Evidence from backward masking and priming. Journal of Memory \& Language, 30, 473-485.

Perfetti, C. A., Bell, L. C., \& Delaney, S. M. (1988). Automatic (prelexical) phonetic activation in silent word reading: Evidence from backward masking. Journal of Memory \& Language, 27, 59-70.

(Manuscript received September 28, 1992.) 